\title{
Effect of ultrasonic vibration and solution-aging treatment on microstructure and properties of in-situ $\mathrm{TiAl}_{3} / 7050 \mathrm{Al}$ composites
}

\author{
Lili Chen ${ }^{1}$, Zhiming Dư ${ }^{1,}$, DanZhao ${ }^{1}$, Lihua Chen² and Changshun Wang ${ }^{2}$ \\ 1School of Material Science and Engineering, Harbin Institute of Technology, Harbin 150001, China \\ 2Technology Center, Beijing North Vehicle Group Corporation, Beijing 100072,China
}

\begin{abstract}
Ultrasonic vibration have positive effect on formation of in-situ $\mathrm{TiAl}_{3} / 7050 \mathrm{Al}$ composites, the role of ultrasound in the reaction process was described systematically. The best solution-aging treatment parameters were discussed and effects of the selected treatment on the resultant microstructure and mechanical properties were investigated. The results show that ultrasonic vibration not only promote the reaction process, but also result in significant spreading particles fallen off from the reaction interface, therefore creating a finer and homogeneous distribution of $\mathrm{TiAl}_{3}$ particles in the composite. In solution process, the skeleton second phase dissolve into matrix with increasing temperature and holding time, the transformation is more sensitive to solution temperature. Residual second phase transform into finer-size rod or discoid shape and a large amount of finer phase $\left(\mathrm{MgZn}_{2}\right.$ and $\mathrm{CuAl}_{2}$ )precipitates after aging-treated. As a result, the strength, hardness and elongation of the composite are slightly increased after using ultrasonic vibration and significantly increased after solution-aging treatment.
\end{abstract}

\section{INTRODUCTION}

Aluminium matrix composites (AMCs) have been recognized as the most popular materials, used for aerospace, automobile, marine and mining industries, and the most promising light alloy among types of metal matrix composites, due to their greater strength, reduced weight, improved high temperature properties, improved abrasion and wear resistance[1-5], etc. The form of reinforcement include particle, whisker or short fiber, continuous fiber and mono filament. Particle-reinforced AMCs are less expensive, superior machining properties, easily to form, more reinforcement to choose and isotropic in nature, compared with other AMCs. Many kinds of particle reinforcements have been studied widely, such as $\mathrm{Al}_{2} \mathrm{O}_{3}$ [6], $\mathrm{SiC}$ [7], $\mathrm{TiB}_{2}$ [8], $\mathrm{MoSi}_{2}$ [9], of which insitu $\mathrm{TiAl}_{3}$ particles has received extensive attentions.

For the interface between reinforcement and $\mathrm{Al}$ matrix is good wettability and clean in in-situ $\mathrm{TiAl}_{3} / \mathrm{Al}$ alloy composite, as well intermetallic compound TiAl3 is very easy to control in Ti-rich condition and suitable to be reinforcement, several methods to fabricate the in-situ $\mathrm{TiAl}_{3} / \mathrm{Al}$ composites have been reported, such as powder metallurgy[10-12], mechanical alloying[13] and casting. Casting has been regarded as a lower cost and higher efficiency method for commercial production. However, composites fabricated by traditional casting usually have uneven distribution of reinforcement, so external energy is introduced. Jiao et al.[14] exerted magnetic field to make the melt a forced movement during the process of in situ generated $\mathrm{Al}_{3} \mathrm{Ti}$ particles reinforced aluminum matrix composites, promoting changes in the conditions

\footnotetext{
a Corresponding author:duzm@263.net
}

of melt dynamics, changing the morphology and distribution. Dinaharan et al. [15] applied friction stir processing to enhance the distribution and morphology of $\mathrm{Al}_{3} \mathrm{Ti}$ and $\mathrm{Al}_{3} \mathrm{Zr}$ particles.

In recent years, ultrasonic vibration has been more effective method to form homogeneous $\mathrm{TiAl}_{3}$ in $\mathrm{Al}$ composite.Liu et al.[16] fabricated in situ $\mathrm{Al}_{3} \mathrm{Ti} / \mathrm{Al}$ composites via ultrasound assisted direct reaction between solid $\mathrm{Ti}$ powers and liquid $\mathrm{Al}$ at $780^{\circ} \mathrm{C}$, the in situ formed $\mathrm{Al}_{3} \mathrm{Ti}$ particles were blocky in morphology, and the size of most $\mathrm{Al}_{3} \mathrm{Ti}$ particles was in the range of 2$7 \mu \mathrm{m}$. Qin et al. [17] studied the formation process of $\mathrm{TiAl}_{3}$ based on the in-situ reaction between globular solid Ti powders with almost uniform size and 2024 Al melt under ultrasonic vibration. Although these studies have been reported, most experiments have been focused on illustrating the formation mechanism of $\mathrm{TiAl}_{3}$ particles during the solidification process, the effects of ultrasonic vibration on fabricating process of in situ $\mathrm{TiAl}_{3} / \mathrm{Al}$ composites were still not discussed sufficiently.

Furthermore, in the case of cast Al alloy, solution heat treatment is frequently recommended to reduce porosity and enhance the properties[18]. However, law of solution-aging treatment on microstructure and mechanical properties of $\mathrm{TiAl}_{3} / \mathrm{Al}$ alloy under selected conditions has not been reported. The experiments described in this work were designed to examine the microstructures and properties of $\mathrm{TiAl}_{3} / \mathrm{Al}$ composites by introducing ultrasonic vibration in molten condition, and to describe the role of ultrasound in the reaction process systematically. Solution-aging treatment was applied to 
explore the best treatment parameters by observing variation of microstructure and mechanical properties.

\section{EXPERIMENTAL}

\subsection{Experimental materials and fabrication of starting composite}

The $\mathrm{TiAl}_{3} / 7050 \mathrm{Al}$ composites were fabricated by in-situ synthesis between globular solid Ti powders with almost uniform size and as-cast 7050Al molten alloy material under ultrasonic vibration. For elemental Ti powder, is sponge titanium powder, the mean particle size was 20 $\mu \mathrm{m}$, and the purity is higher than $99.5 \%$. For $7050 \mathrm{Al}$ alloy, the nominal chemical composition includes $6.624 \% \mathrm{Zn}, \quad 1.960 \% \mathrm{Mg}, \quad 2.280 \% \mathrm{Cu}, \quad 0.0975 \% \mathrm{Zr}$, $0.093 \% \mathrm{Si}, 0.132 \% \mathrm{Fe}, 0.074 \% \mathrm{Cr}$ and balance of $\mathrm{Al}($ in wt.\%). The as-cast block 7050Al alloy was melt in crucible resistance furnace at $750^{\circ} \mathrm{C}$ and refined 1 minute by refining agent $\left(55 \% \mathrm{KCl}, 5 \% \mathrm{CaF}_{2}, 40 \% \mathrm{NaCl}\right.$, about $2 \%$ of melt, in wt.\%). Subsequently, the Ti powders wrapped with $\mathrm{Al}$ foil were added into the melt, meanwhile ultrasonic equipment was opened. The amount of additive $\mathrm{Ti}$ corresponded to the composition of $6 \mathrm{wt} \% \mathrm{TiAl}_{3} / 2024$ Al composite. Ultrasonic vibration with power of $1.5 \mathrm{~kW}$ and frequency of $20 \mathrm{kHz}$ was introduced into the molten alloy, the reaction can be accelerated and adequately proceeded. After 5-20 min, the molten alloy was rapidly poured into a steel mold under gravity to cast an ingot with dimension of $\Phi 50 \mathrm{~mm} \times \mathrm{h} 60 \mathrm{~mm}$. Samples for microstructure examination and following treatment and property-test were cut from the casting ingots, and prepared by standard metallographic technique of grinding with $\mathrm{SiC}$ abrasive and polishing with a diamond spray $(0.5 \mu \mathrm{m})$.

\subsection{Solution-aging processing}

Solution treatment was carried out at $450-500^{\circ} \mathrm{C}$ in 30 $120 \mathrm{~min}$ for the $\mathrm{TiAl}_{3} / 7050 \mathrm{Al}$ composites, quenching in water at $20^{\circ} \mathrm{C}$ and then artificial aging at $120-195^{\circ} \mathrm{C}$ for different time intervals from $3 \mathrm{~h}$ up to $24 \mathrm{~h}$. After above treatment, the samples were slightly chemically etched to remove the surface oxide layer. The etching agent was an aqueous solution of $2.5 \mathrm{vol} . \% \mathrm{HNO}_{3}+0.5 \mathrm{vol} . \% \mathrm{HF}$.

\subsection{Mechanical testing and microstructure characterization}

Tensile tests were carried out (by universal material testing machine, Instron-5569R ) at room temperature using round specimens machined from the ingot with a gage section of $\Phi 6 \mathrm{~mm} \times 24 \mathrm{~mm}$. The initial strain rate at room temperature was $1 \times 10^{-4} \mathrm{~s}^{-1}$. Hardness tests were performed on a HB-3000B (load of $62.5 \mathrm{~kg}$ and $500+62.5 \mathrm{~kg}$, before and after treatment, respectively. $30 \mathrm{~s}$ dwell time) on cross sections. Both above, at least five tests were performed and average values were reported.

The microstructures of in-situ and solution-aging treatment samples were carried out by scanning electron
microscopy(SEM) (Quanta2000) equipped with energy dispersive spectroscopy(EDS), transmission electron microscopy (TEM) (Talos F200x, USA). Specimens for TEM observation were prepared using a standard procedure and an jet polisher.

\section{RESULTS AND DISCUSSION}

\subsection{Microstructure of in-situ $\mathrm{TiAl}_{3} / 7050 \mathrm{Al}$ composites with ultrasonic vibration}

Microstructure of in-situ $\mathrm{TiAl}_{3} / 7050 \mathrm{Al}$ composites with and without ultrasonic vibration are shown in Fig. 1a and $b$, respectively. It can been clearly seen that the distribution of block-shaped $\mathrm{TiAl}_{3}$ particles with regular appearance is more homogeneous and the particles are smaller in composite with ultrasonic vibration(Fig.1(a)), while network linked by skeleton-shape second phase (TEM analysis proved $\mathrm{Al}_{2} \mathrm{CuMg}$ and $\mathrm{CuAl}_{2}$ ) distribute in the composite evenly. In contrast, $\mathrm{TiAl}_{3}$ particles present large-sized and gather with each other in the composite without ultrasonic vibration(Fig.1(b)), indicating ultrasonic vibration promote the reaction process and dispersion of $\mathrm{Ti}$, therefore creating a homogeneous distribution of $\mathrm{TiAl}_{3}$ particles in the $\mathrm{Al}$ matrix.
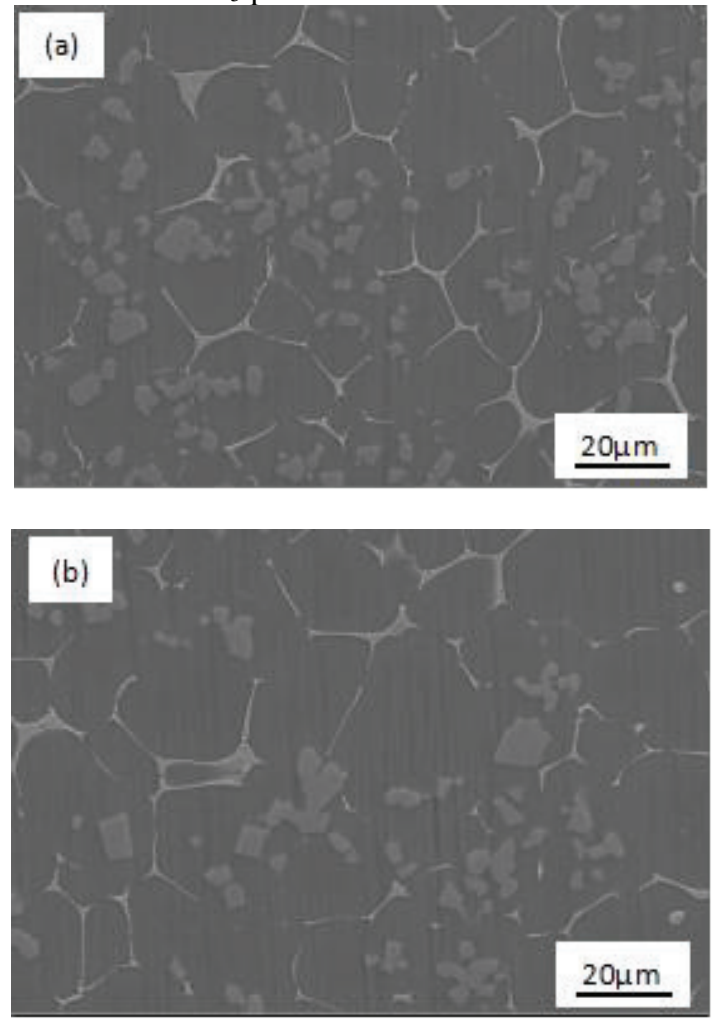

Fig.1 microstruture of in-situ $\mathrm{TiAl}_{3} / 7050 \mathrm{Al}$ composites (a)with ultrasonic vibration; (b)without ultrasonic vibration

In Qin Y's work[11], the formation of $\mathrm{TiAl}_{3}$ particles at the $\mathrm{Al}$ melt/Ti interface has been studied. For the reason of inter-diffusion and reaction of $\mathrm{Ti}$ and $\mathrm{Al}$ atoms, $\mathrm{TiAl}_{3}$ layer is formed on the surface of Ti powder. Cracks can make the layer peel off when the layer thickness increases to a certain threshold. Consequently, the brittle $\mathrm{TiAl}_{3}$ layer is ruptured into small particles more easily and quickly when we add ultrasonic vibration in the 
process of composite formation. Fig.2 shows high magnification SEM micrograph of $\mathrm{TiAl}_{3}$ particle, the circle region is Ti-rich region, while the peripheral area Ti:Al approximately equal $3: 1($ at $\%)$ by EDS element scanning, indicating peripheral area is $\mathrm{TiAl}_{3}$ layer which has not fall off, the thickness is about $2 \mu \mathrm{m}$.

When ultrasonic act on the melt, due to cavitation effect, the reaction system will form a large number of hot spots which produce high temperature and high pressure. The temperature and pressure ensure reaction substances high activity by ionization and free radical reaction, which greatly accelerates the reaction process of Ti-Al system. The local high temperature regions, favourable wetting effect between Ti powders and liquid, decrease the surface tension of the liquid and thus promote the solid-liquid reaction. In addition, strong turbulence produced by high pressure impact on $\mathrm{Ti} / \mathrm{Al}$ interface to make the reaction activity of $\mathrm{Ti}$ powder increased greatly. Moreover, the acoustic streaming and cavitation generated $\mathrm{TiAl}_{3}$ falling off from the reaction interface quickly and more uniform particle distribution in the matrix, instead of converging together. With the increasing of ultrasonic power(CS0,0.6,0.9,1.2,1.5KW), the particle size distribution is more finer, larger size $(>10 \mu \mathrm{m})$ is less and less, intermediate size $(5-10 \mu \mathrm{m})$ and smaller size $(<5 \mu \mathrm{m})$ are more and more, as shown in Fig.3.

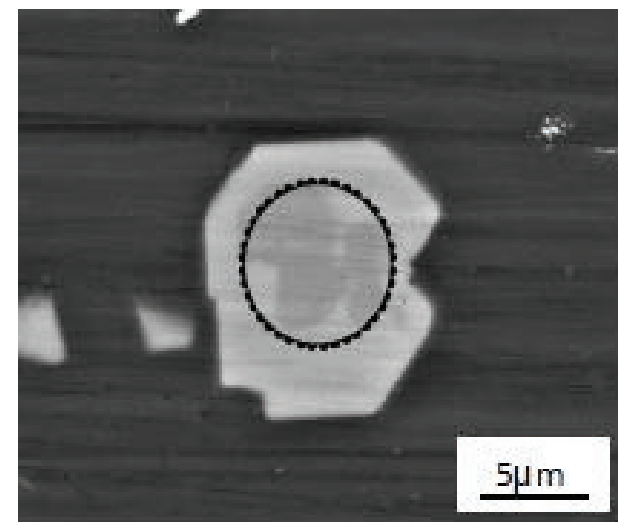

Fig.2 High magnification SEM of particle

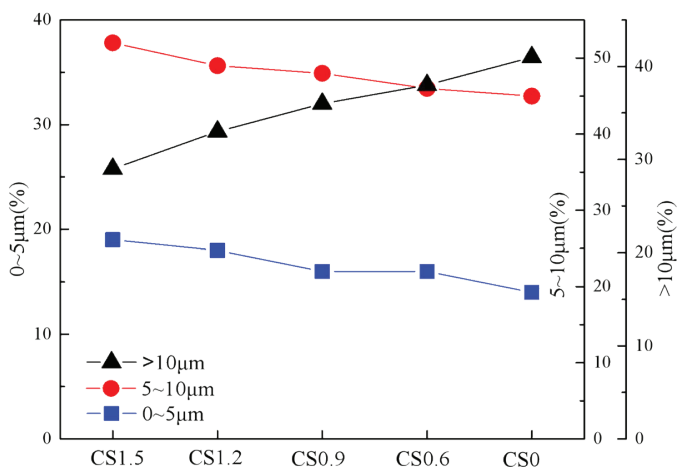

Fig.3 Particle size distribution with ultrasonic power

\subsection{Composite microstructure evolution during solution treatment}

Fig.4 shows microstructure images of solution-treated composite at $450^{\circ} \mathrm{C}$ in different time(30-60min). The second phase (TEM analysis proved $\mathrm{Al}_{2} \mathrm{CuMg}$ and $\mathrm{CuAl}_{2}$ ) network linked by skeleton-shape which distribute in the as-cast composite evenly break and decrease with time during heating at $450{ }^{\circ} \mathrm{C}$. The volume fraction of second phase is less than $0.5 \%$ after solution-treated in $120 \mathrm{~min}$, compared with $4.1 \%$ in the as-cast composite by ImagePro Plus 6.0 software. As the heating time increase, the second phase dissolve into the matrix. Fig.5 represents microstructure images of solution-treated composite at different temperatures for $90 \min \left(470-500^{\circ} \mathrm{C}\right)$. We can conclude variation law of second phase with increasing temperature keep in touch with increasing holding time, the transformation is more sensitive to solution temperature. When the temperature reaches $480^{\circ} \mathrm{C}$, only few skeleton-shape phase left. Table 1 lists the Matrix composition of composites heated at $450^{\circ} \mathrm{C}$ for different time, element $\mathrm{Mg}, \mathrm{Cu}, \mathrm{Zn}$ etc, resolve into the matrix. The weight percent of element in matrix augments with increasing the solution time, while the network second phase decreases.
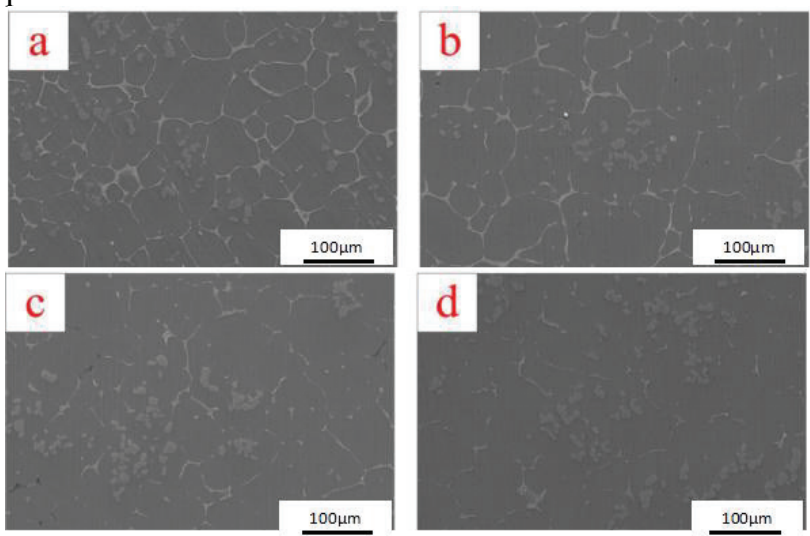

Fig.4 Microstructure image of solution-treated composite at $450^{\circ} \mathrm{C}$ in different time(a)30min;(b)60min;(c) 90min;(d) $120 \mathrm{~min}$

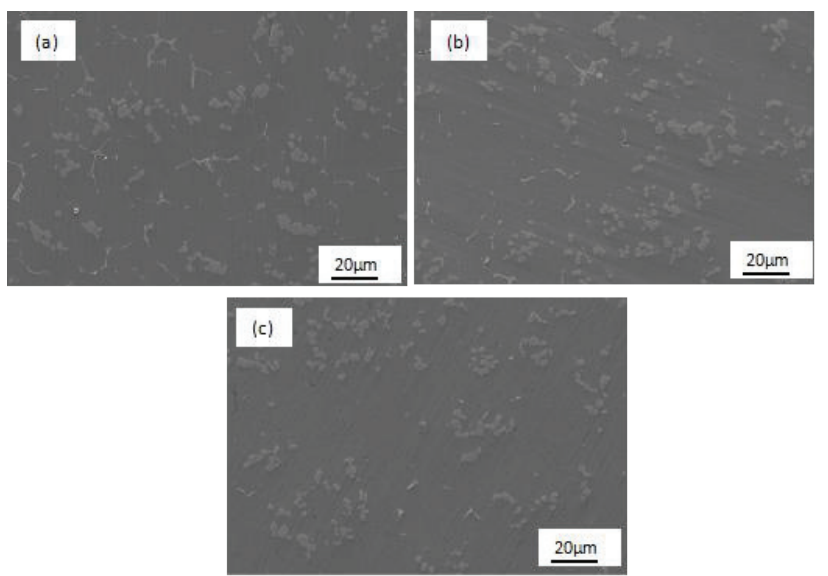

Fig.5 Microstructure image of solution-treated composite at different temperatures for $90 \min (\mathrm{a}) 470^{\circ} \mathrm{C}$;(b) $480^{\circ} \mathrm{C}$; (c) $500^{\circ} \mathrm{C}$ 
Table 1 Matrix composition of composites heated at $450^{\circ} \mathrm{C}$ for different time $(\mathrm{Wt} \%)$

\begin{tabular}{llllllllll}
\hline Heating time/min & $\mathrm{Mg}$ & $\mathrm{Si}$ & $\mathrm{Ti}$ & $\mathrm{Cu}$ & $\mathrm{Zn}$ & $\mathrm{Zr}$ & $\mathrm{Fe}$ & $\mathrm{Cr}$ & $\mathrm{Al}$ \\
\hline 30 & 1.41 & 0.04 & 9.87 & 1.49 & 5.08 & 0.35 & - & - & 81.76 \\
60 & 1.50 & 0.05 & 9.65 & 1.62 & 5.38 & 0.038 & 0.08 & - & 81.68 \\
90 & 1.62 & 0.07 & 9.02 & 1.80 & 5.62 & 0.042 & 0.07 & 0.02 & 81.74 \\
120 & 1.78 & 0.083 & 9.80 & 1.83 & 5.64 & 0.05 & 0.10 & 0.02 & 80.7 \\
\hline
\end{tabular}

\subsection{Effect of aging treatment on microstructure and mechanical properties}

Microstructure image of aging-treated composite are shown in Fig.6, residual skeleton-shape second phase generated in as-cast composite transform into finer-size rod or discoid shape after aging-treated (white-bright ones in Fig.6a), instead of dissolving into matrix absolutely. These residual second phase are usually distributed around grain boundary, while intragranular ones are redissolved into matrix completely during solution treatment process. Besides, a large amount of finer phase precipitates(with an average size of 20nm) along the grain boundary during the aging process, morphology of precipitates is shown in Fig.6b. Consequently, TEM analysis proves that precipitates are $\mathrm{MgZn}_{2}$ and $\mathrm{CuAl}_{2}$.

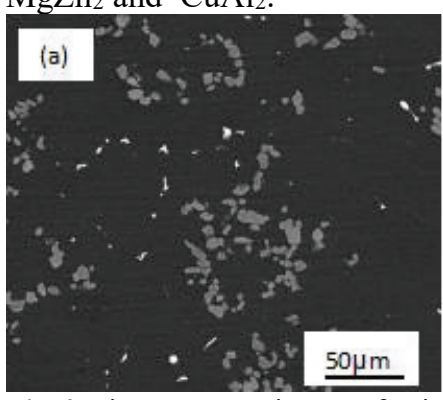

(b)

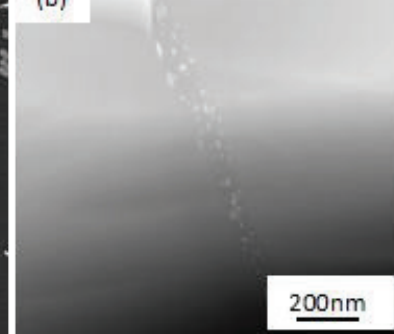

Fig.6 Microstructure image of aging-treated composite low magnification;(b)morphology of precipitates

Consult solution-aging treatment technology of $7050 \mathrm{Al}$ alloy substrate, the strength and hardness variation pattern are investigated at aging temperature $120^{\circ} \mathrm{C} 、 145^{\circ} \mathrm{C} 、 160^{\circ} \mathrm{C} 、 195^{\circ} \mathrm{C}$ for $12 \mathrm{~h}$ followed by $480^{\circ} \mathrm{C} / 60 \mathrm{~min}$ solution-treated, as shown in Fig.7. Both variation present descend with improved temperature, therefore $120^{\circ} \mathrm{C}$ is concerned as the best aging temperature. Since grain size is coarsen under high temperature, performance degrade distinctly. In addition, the effect of aging time(from $3 \mathrm{~h}$ to $24 \mathrm{~h}$ ) on properties is studied, as shown in Fig.8. When aging time is short, the curve of ultimate strength(UTS), yield strength(YS) and hardness ascend with increasing aging time. In fact, the composite is strengthen by precipitates continuously increasing. Until aging time reaches $18 \mathrm{~h}$, precipitate is no

longer increased, the curves start to appear decline tendency. So $18 \mathrm{~h}$ is concerned as peak aging time. Most important, elongation has relatively high valve(8.03\%). As a result, the best treatment of in-situ wt. $6 \% \mathrm{TiAl}_{3} / 7050 \mathrm{Al}$ composites with ultrasonic vibration is: $500^{\circ} \mathrm{C} / 60 \mathrm{~min}+120^{\circ} \mathrm{C} / 18 \mathrm{~h}$, as Table 2 shown, al properties of composites in different treatment. For comparing, values of as-cast without ultrasonic vibration and un-treated samples are also listed. Evidently, the ultrasonic power influences slightly the strength and elongation of composite. Moreover, comparing with the properties of the composite without subject to solutionaging treatment, the UTS,YS, elongation and hardness of the composite processed solution-aging are improved greatly, by $174 \%, 165 \%, 143 \%$ and $129 \%$, respectively.

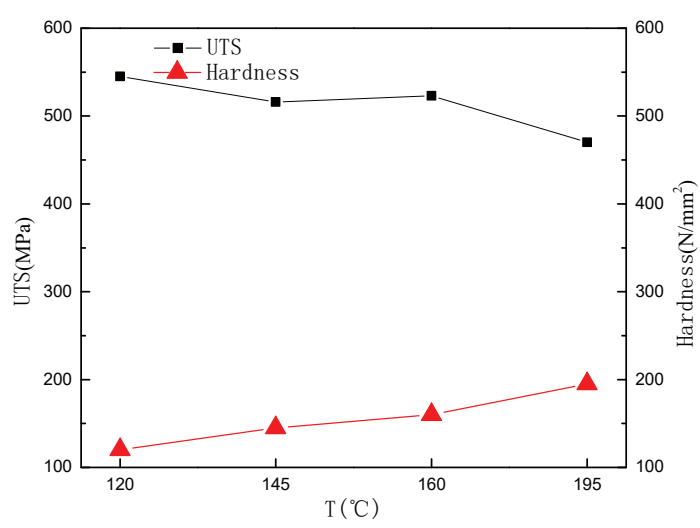

Fig.7 The strength and hardness variation pattern

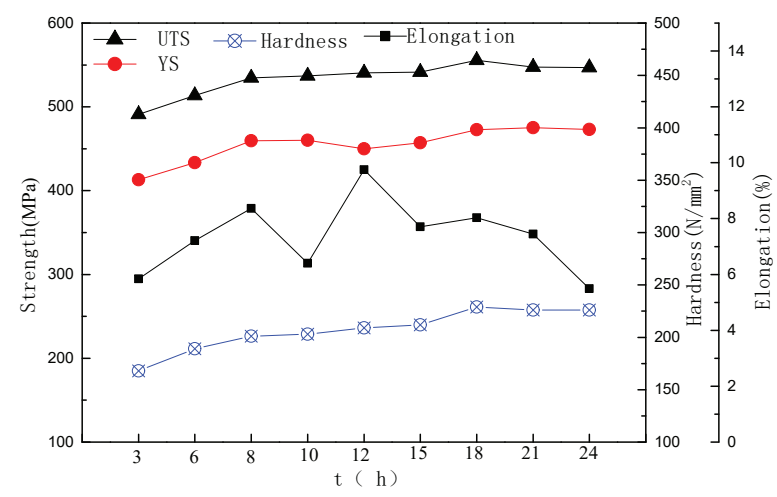

Fig.8 Effect of aging time on properties 
Table 2 Mechanical properties of composites in different treatment

\begin{tabular}{lllll}
\hline sample & UTS(MPa) & YS(MPa) & Elongation(\%) & Hardness(N/mm2) \\
\hline $480^{\circ} \mathrm{C} / 60 \mathrm{~min}+120^{\circ} \mathrm{C} / 18 \mathrm{~h}$ & 555.5 & 472.7 & 8.03 & 229 \\
$480^{\circ} \mathrm{C} / 90 \mathrm{~min}+120^{\circ} \mathrm{C} / 18 \mathrm{~h}$ & 541.0 & 459.1 & 7.20 & 212 \\
$480^{\circ} \mathrm{C} / 120 \mathrm{~min}+120^{\circ} \mathrm{C} / 18 \mathrm{~h}$ & 572.2 & 467.0 & 10.42 & 232 \\
$500^{\circ} \mathrm{C} / 30 \mathrm{~min}+120^{\circ} \mathrm{C} / 18 \mathrm{~h}$ & 558.1 & 484.2 & 6.31 & 229 \\
$500^{\circ} \mathrm{C} / 60 \mathrm{~min}+120^{\circ} \mathrm{C} / 18 \mathrm{~h}$ & 582.0 & 496.1 & 11.20 & 236 \\
As-cast with ultrasonic vibration & 320 & 286 & 5.6 & 178 \\
As-cast without ultrasonic vibration & 237 & 224 & 4.28 & 113 \\
\hline
\end{tabular}

\subsection{Discussion}

The properties of $\mathrm{TiAl}_{3} / 7050 \mathrm{Al}$ composite are determined by $\mathrm{TiAl}_{3}$ particles, $\mathrm{Al}$ matrix and their combination. The composite applied ultrasonic vibration possess much finer $\mathrm{TiAl}_{3}$ particles and more homogeneous particle distribution, consequently their properties are slightly increased compared with those without ultrasonic vibration. After solution-aging treatment, morphology of $\mathrm{TiAl}_{3}$ particles is stability without any change, on the contrary variation have taken place in matrix and second phase. These variation cause properties of $\mathrm{TiAl}_{3} / 7050 \mathrm{Al}$ composite after solution-aging treatment enhanced greatly compared with the as-cast ones(shown in table 2).

The main strengthen reason obtained direct evidence from our work is as followed. Firstly, when the in-situ $\mathrm{TiAl}_{3}$ particle reinforced composite fabricated, the interface bonding between $\mathrm{TiAl}_{3}$ particle and $\mathrm{Al}$ matrix is investigated, as shown in Fig.9. Morphology of $\mathrm{TiAl}_{3}$ particle in Al matrix(Fig.9a), combined with Fig.1 a, $\mathrm{TiAl}_{3}$ reinforcement with high strength and hardness is distributed in matrix evenly, result in dispersion strengthening effect. Furthermore, HRTEM of interface bonding depicts coherent relationship between $\mathrm{TiAl}_{3}$ particle and Al matrix(Fig.9b), owing to the in-situ synthesis between Ti powders and 7050Al molten alloy. In fact, the in situ reinforcements are ultra fine and more compatible with the matrix, the interface is cleaner than that of composites conventionally. Because the in-situ formed particulates are thermally stable, this will ensure that the composite matrix has sufficient strength to transfer stress.

Secondly, solid solution strengthening and supersaturation degree of the matrix is enhanced via solution-treated. Element $\mathrm{Mg}, \mathrm{Cu}, \mathrm{Zn}$ etc, resolve into the matrix, result in lattice deformation and energy raising. As a result, dislocation motion become difficult in plastic deformation. Thirdly, a large amount of finer phase precipitates along the grain boundary during the aging process, result in dispersion strengthening effect similarly.

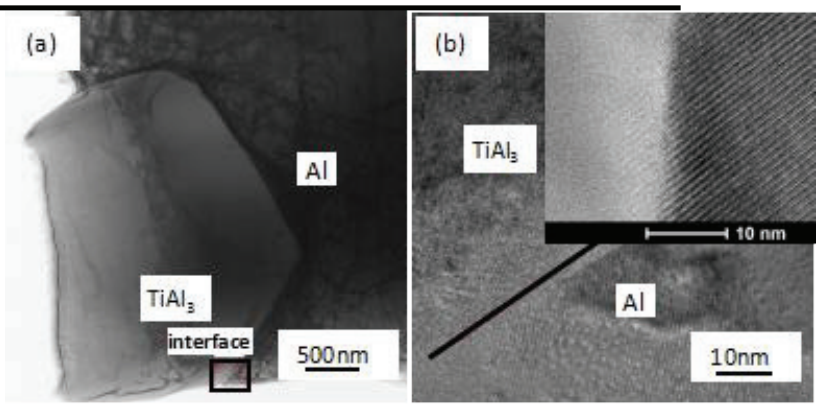

Fig.9 Interface bonding between $\mathrm{TiAl}_{3}$ particle and $\mathrm{Al}$ matrix (a)morphology of $\mathrm{TiAl}_{3}$ particle in Al matrix; (b)HRTEM of interface

\section{CONCLUSIONS}

$\mathrm{TiAl}_{3} / 7050 \mathrm{Al}$ composites can be certainly obtained by using the selected conditions, the microstructure of ascast composite consists of $\mathrm{TiAl}_{3}$ particles, skeleton-shape second phase $\left(\mathrm{Al}_{2} \mathrm{CuMg}\right.$ and $\left.\mathrm{CuAl}_{2}\right)$ and $7050 \mathrm{Al}$ matrix.

(1)In the fabrication of $\mathrm{TiAl}_{3} / 7050 \mathrm{Al}$ composites, ultrasonic vibration have positive effect on formation of $\mathrm{TiAl}_{3}$ particles, it can not only promote the reaction process, but also create finer particles and distribution of $\mathrm{TiAl}_{3}$ particles more evenly.

(2)After solution treatment, skeleton-shape second phase break and disappear with increasing heating temperature and holding time, accordingly more and more element $\mathrm{Mg}, \mathrm{Cu}, \mathrm{Zn}$ etc. resolve into matrix. Solid solution strengthening and supersaturation strengthening enhance the composite. after aging, residual second phase transform into finer-size and a large amount of finer precipitates $\left(\mathrm{MgZn}_{2}\right.$ and $\left.\mathrm{CuAl}_{2}\right)$ make the composite strengthen further. The best solution-aging treatment parameters for the designated composite were: $500^{\circ} \mathrm{C} / 60 \mathrm{~min}+120^{\circ} \mathrm{C} / 18 \mathrm{~h}$.

(3)The properties of the composite are slightly increased after applying ultrasonic vibration and significantly increased after solution-aging treatment. The best UTS,YS, elongation and hardness of the composite are improved by $174 \%, 165 \%, 143 \%$ and $129 \%$, respectively. 


\section{Acknowledgements}

The authors express their appreciation for financial support of Ministry of science and technology project of international cooperation under Grant(No.2014***50320).

\section{References}

1. Surappa M K . Sādhanā. 28,1(2003):319-334

2. Ervina Efzan M N, Siti Syazwani N, Mustafa A B A M. Key Eng. Mater.700(2016):102-110

3. Deaquino-Lara R, Soltani N, Bahrami A, et al. Mater. Des. 67,1(2015):224-231

4. Adamiak M, Tomiczek B, Górka J, et al.Arch. Metall. Mater. 61,2(2016):847-852

5. Kala H, Mer K K S, Kumar S. Procedia Mater. Sci. 6(2014):1951-1960

6. Su H, Gao W, Feng $\mathrm{Z}$, et al. Mater. Des. 36(2012):590-596

7. Xu H, Palmiere E J. Composites Part A Applied Science \& Manufacturing. 30,3(1999):203-211

8. Kumar S, Chakraborty M, Sarma V S, et al. Wear, 265,1-2(2008):134-142

9. Corrochano J, Lieblich M, Ibáñez J. Composites Part A Applied Science \& Manufacturing. 42,9(2011):1093-1099

10. Nofar M, Hosseini H R M, Kolagar-Daroonkolaie N. Mater. Des. 30,2(2009):280-286

11. Qin Y, Chen T, Wang Y, et al.Materials. 9,3 (2016):199

12. Chianeh V A, Hosseini H R M, Nofar M. J. Alloys Compd. 473,1-2(2009):127-132

13. Al-Dabbagh J B, Tahar $\mathrm{R}$ M, Ishak $\mathrm{M}$, et al. International Journal of Nanoelectronics \& Materials.8,1(2015):23-32

14. Jiao L, Zhao Y T, Wu Y, et al. Advanced Materials Research.600(2012):199-203

15. [15]Dinaharan I, Kumar G A, Vijay S J, et al. Mater. Des. 63,21(2014):213-222

16. Liu Z, Han Q, Li J. Powder Technol. 247(2013):5559

17. Qin J, Chen G, Wang B, et al. J. Alloys Compd.653(2015):32-38

18. Liu D, Atkinson H V, Kapranos P, et al. J. Mater. Sci. 39,1(2004):99-105 